\title{
MINT ülkelerinde savunma harcamaları ve ekonomik büyüme ilişkisi: Panel nedensellik analizi
}

\section{The relationship between defence expenditures and economic growth in MINT countries: A panel causality analysis}

1 Dr. Öğr. Üyesi, Hakkari Üniversitesi, Hakkari, Türkiye,

selimdemez@hakkari.edu.tr

ORCID: 0000-0001-6885-0499

\footnotetext{
2 Arş. Gör., Hakkari Üniversitesi, Hakkari, Türkiye, ibrahimppolat@gmail.com
}

ORCID: 0000-0001-9785-160X

\section{Sorumlu Yazar/Corresponding Author:}

Selim Demez,

Dr. Öğr. Üyesi, Hakkari Üniversitesi, Hakkari, Türkiye,

selimdemez@hakkari.edu.tr

Başvuru/Submitted: 6/06/2021

1. Revizyon/ $\mathbf{1}^{\text {th }}$ Revised: $4 / 07 / 2021$

2. Revizyon/ $2^{\text {nd }}$ Revised: $1 / 08 / 2021$

Kabul/Accepted: 8/08/2021

Yayın/Online Published: 25/09/2021

Atıf/Citation: Demez, S., \& Polat, İ.H., 8TMINT ülkelerinde savunma harcamaları ve ekonomik büyüme ilişkisi: Panel nedensellik analizi, bmij (2021) 9 (3): 1032 1044, doi: https://doi.org/10.15295/bmij.v9i3.1871

\author{
Selim Demez ${ }^{1}$ \\ İbrahim Halil Polat ${ }^{2}$
}

Öz

Tüm ülkeler iç ve dış güvenliğini temin etmek için savunma harcaması yapmak zorundadır. Bu harcamalar kamu harcaması niteliğinde olup çıktı üzerindeki etkisi ekonomi literatüründe üzerinde oldukça fazla durulan bir konudur. Çünkü bu harcamalar tam anlamıla toplumdaki bireylerin refah düzeylerini artırmak amacıyla yapılan harcamalar olmamakla beraber vergi gelirleri ile finanse edilmektedirler. Bu çalışmada 1974 - 2019 yılları arasında MINT ülkeleri için (Meksika, Endonezya, Nijerya ve Türkiye) savunma harcamaları ekonomik büyüme ilișkisi Emirmahmutoğlu ve Köse (2011) heterojen panel nedensellik analizi ile test edilmiştir. Test sonuçlarına göre Meksika'da büyüme ile savunma harcamaları arasında çift yönlü nedensellik vardır. Türkiye'de ise savunma harcamalarından büyümeye doğru tek yönlü nedensellik ilişkisine rastlanmıştır. Panelin geneli için ise savunma harcamalarından büyümeye doğru tek yönlü nedensellik vardır. MINT ülkelerinde savunma harcamalarının ekonomik büyümeyi pozitif yönde etkilediği hipotezinin geçerli olduğu söylenebilir. Endonezya ve Nijerya'da ise yansızlık hipotezi geçerlidir.

Anahtar Kelimeler: Savunma Harcamaları, Büyüme, Panel Nedensellik Analizi, MINT Ülkeleri

Jel Kodları: C33, E31, E43

\begin{abstract}
All countries have to spend on defence to ensure their internal and external security. These expenditures are like public expenditures, and their effect on output is a subject that is highly emphasized in the economic literature. Because these expenditures are not precisely the expenditures made to increase the welfare of the individuals in the society, but tax revenues finance them. This study tested the relationship between defence expenditures and economic growth for MINT countries (Mexico, Indonesia, Nigeria and Turkey) between 1974 and 2019 by Emirmahmutoğlu and Köse (2011) heterogeneous panel causality analysis. According to the test results, there is bidirectional causality between growth and defence expenditures in Mexico. In Turkey, on the other hand, a one-way causality relationship was found from defence expenditures to growth. For the panel in general, there is a unidirectional causality running from defence expenditures to growth. Therefore, It can be said that the hypothesis that defence expenditures positively affect economic growth in MINT countries is valid. In Indonesia and Nigeria, the neutrality hypothesis is valid.
\end{abstract}

Keywords: Military Expenditures, Growth, Panel Causality Analysis, MINT Countries

Jel Codes: C33, E31, E43 


\section{Extended Abstract}

\section{TThe relationship between defence expenditures and economic growth in MINT countries: A panel causality analysis}

\section{Literature}

It is essential to investigate the effects of defence expenditures on economic growth. First of all, defence expenditures can be a prerequisite for economic growth since it means ensuring security. The importance of the relationship between defence expenditures and economic growth is based on two views. One of them is the necessity of assessing the cost of defence in terms of growth or reduction in current consumption, investment or output, even if the optimal level of defence spending can be determined. The other is that defence expenditures have positive external effects in other areas of the economy, especially in infrastructure, technological development and human capital accumulation. Therefore, expanding the cost of change by shifting scarce resources from areas that do not directly contribute to current consumption, investment, and economic growth with positive external benefits remain an essential research topic. The summary of these studies in question; Some of these studies (Benoit, 1973; Murdoch, Chung \& Sandler, 1997; Sezgin, 2001; Rafael, 2001; Ateşoğlu, 2002; Halıcıŏ̆lu, 2004; Yıldırım, Sezgin \& Öcal, 2005; Sümer, 2005; Wijeweera \& Webb, 2009; Feridun, Sawhnney \& Shahbaz, 2011; Yurttançıkmaz, Amin \& Emsen, 2012; Yildırım \& Öcal, 2016; Canbay \& Mercan, 2017; Ismail, 2017; Oarania \& Sandar, 2020) while others defend the Keynesian approach (Smith, 1980; Değer, 1986; Gyimah-Brempong, 1989; Dunne \& Vougas, 1999; Batchelor, Dunne \& Saalet, 2000; Galvin, 2003; Karagöl \& Palaz, 2004; Yakoulev, 2007; Alptekin \& Levine 2012; Başar \& Kını, 2012; Khalid \& Razaq, 2015; Na \& Bo, 2013; Altay, Ekinci \& Peçe, 2013; Özsagir, 2013; Jabar, Khalid \&Razaq, 2015; Korkmaz, 2015; Manamperi, 2016; Topal, 2018; Saba and Ngepah, 2020 ; Azam, 2020) refers to the Neoclassical Approach. On the other hand, some studies (Biswas \& Ram, 1986; Dunne \& Nikolaidou, 2012; Papanikos, 2015; Kollias \& Paleologou 2016;) state no significant relationship between the variables in question or that this relationship between the variables is negligible.

\section{Research subject}

Defence spending is a public expenditure item that all countries have to make. Therefore, the effect of expenditures on output is significant. Therefore, the policies to be implemented will be effective if they are shaped by the results obtained from the analysis of the relationship between defence expenditures and economic growth. For this reason, the subject of the study is to determine the direction of the relationship between defence expenditures and economic growth.

\section{Research purpose and importance}

This study aims to determine the output relationship of defence or military expenditures, one of the sub-items of public expenditure, which countries have to do to ensure security and peace. Although military expenditures are seen as an expense item within the framework of traditional theory, they can significantly contribute to the country's economy in the long run. For example, a missile system or drone is military expenditure. However, high income can be obtained from the sale of it. In other words, the expected decrease in total welfare can be a driving force that can be used to increase output. At this point, whether military expenditures bring growth or growth brings military expenditures is sought for the MINT country group. It is thought that this situation will add an alternative perspective to the growth and development policies of the countries. We chose the MINT country group because there has been no study on the subject for this country group, and this country group is similar to each other in many respects.

\section{Contribution of the article to the literature}

Although the relationship between defence expenditures and economic growth has been the subject of many empirical studies, the direction of the relationship between the two variables has not been determined precisely, and it varies according to studies. In this study, four different countries from four regions, which are among the countries with the highest military spending in the world, were included in the sample and analyzed. It is thought to be important because it is one of the first studies in the economics literature for MINT countries, and that the panel result supports the Keynesian view in some countries and that this country group limits investments in other areas.

\section{Design and method}

\section{Research type}

This article is a research article.

\section{Research problems}

The research question was determined as "for this group of countries in question, revealing how defence expenditures affect economic growth. Is defence spending positive for economic growth? Is it negative or does it not affect it?" seeks answers to the questions.

\section{Data collection method}

Data obtained for the study and obtained from the World Bank database.

\section{Quantitative/qualitative analysis}

In this study, the relationship between defence expenditures and economic growth in MINT countries was tested by Emirmahmutoğlu and Köse (2011) heterogeneous panel causality analysis

\section{Research model}

$$
\begin{array}{ll}
G D P_{i t}=\alpha_{i}+\beta_{i} M E_{i t}+\mu_{i t} & \Rightarrow i=1,2, \ldots, N \text { ve } t=1,2, \ldots, T \\
D E_{i t}=b_{i}+\theta_{i} G D P_{i t}+\varepsilon_{i t} & \Rightarrow i=1,2, \ldots, N \text { ve } t=1,2, \ldots, T
\end{array}
$$

\section{Research hypotheses}

This research hypothesis was determined as follows; 
Ho: "There is bidirectional causality between growth and defence spending in Mexico. In Turkey, on the other hand, a one-way causality relationship was found from defence expenditures to growth. There is a unidirectional causality running from defence spending to growth for the panel as a whole."

\section{Findings and discussion}

According to the test results, there is bidirectional causality between growth and defence expenditures in Mexico. In Turkey, on the other hand, a one-way causality relationship was found from defence expenditures to growth. For the panel in general, there is a unidirectional causality running from defence expenditures to growth. Therefore, It can be said that the hypothesis that defence expenditures positively affect economic growth in MINT countries is valid. In Indonesia and Nigeria, the neutrality hypothesis is valid.

\section{Conclusion, recommendation and limitations}

The defence expenditures for MINT countries, which consist of four countries (Mexico, Indonesia, Nigeria and Turkey) and Turkey, support the traction growth hypothesis, thus the Keynesian view. The neutrality hypothesis is valid for Nigeria and Indonesia. In addition, both growth-pull and defence expenditures-pull growth hypotheses are valid since Mexico's growth, and defence expenditures affect each other. According to the results obtained in this context, the study showed consistency with many studies in the literature. From an economic point of view, the results obtained emphasize the positive effect of military expenditures on economic growth in Turkey as a developing country. In this country group, including Turkey, it is recommended that countries with foreign trade deficits in the defence industry develop policies to increase domestic production. Because, in terms of our position and international trade, investing in the national defence industry will positively contribute to the countries in terms of national security and trade balance. However, the pressure of increasing defence expenditures on other social expenditures such as health, infrastructure and education should not be ignored. 


\section{Giriş}

Tarih boyunca tüm ülkeler muhtemel her türlü iç ve dış tehditlere karşı savunma harcamaları (SH) yapmak zorunda kalmışlardır. XX. yüzyılın ilk yarısında meydana gelen dünya savaşları ve sonrasında yaşanan soğuk savaşın dünya genelinde yarattığı endişe SH'nin önemini arttırmıştır. 1990'1 y ylların başlarında soğuk savaşın görünürdeki etkilerinin ortadan kalkmasıyla birlikte SH azalıyormuş gibi görünse de aslında sadece üstü kapatılmış, kamuoyundan gizli bir şekilde artarak devam etmiştir (Dunne ve Nikolaidou, 2012: 48). SIPRI (Stockholm Uluslararası Barış Araştırmaları Enstitüsü) raporlarına göre 2017 yılı itibariyle dünya genelinde toplam 1 trilyon 733 milyar dolarlık SH yapılmıştır. Bu harcamalar arasında en büyük pay 632 milyar dolarla Kuzey Amerika'ya aittir. İkinci sırada 325 milyar dolar ile Doğu Asya kıtası yer alırken, üçüncü sırada 242 milyar dolar SH yapan Batı Avrupa bölgesi gelmektedir. Bazı iç ve dış karışıklarla karşı karşıya olan ülkelerde ise SH toplam bütçe harcamalarının neredeyse yarısına karşılık gelmektedir. Buna ek olarak SH güvenli bir iş ortamı anlamına geldiğinden ülkelerin ekonomik büyüme (EB) hedeflerine ulaşmada önemli bir koşul olarak değerlendirilebilmektedir (Saunders, 1993: 26).

Yukarıda belirtilen sebeplerden dolayı SH ile EB ilişkisi iktisatçıların da üzerinde önemle durdukları konulardan biridir. Her ne kadar bu ilişkinin varlığı konusunda literatürde bir fikir birliği varsa da ilişkinin yönü ve etkileri değişkenlik göstermektedir. Literatürde $\mathrm{SH}^{\prime}$ nin büyümeyi nasıl ve ne yönde etkilediği konusunda dört farklı hipotez yer almaktadır. Bu hipotezler SH'den EB'ye doğru tek yönlü nedensellik, EB' den SH'ye doğru tek yönlü nedensellik, SH ile EB arasında çift yönlü nedensellik ve SH ile EB arasında herhangi bir nedensellik ilişkisinin bulunmadığı şeklindedir. Bu dört hipotezin farklı politik sonuçları olmasından dolayı SH ile EB arasındaki ilişkinin ortaya konulması, ekonomik açıdan uygun stratejilerin ve politikaların belirlenmesi bakımından büyük önem arz etmektedir (Pan, Chang ve Rufael, 2015: 443-444).

MINT ülkeleri için ele alınan bu çalışmanın amacı ülkelerin kendi güvenliklerini ve huzurlarını temin etmek için yapmak zorunda oldukları ve kamu harcama alt kalemlerinden biri olan savunma ya da askeri harcamaları ile çıktı arasındaki ilişkiyi tespit etmektir. Söz konusu askeri harcamalar geleneksel teori çerçevesinde tam anlamıla bir gider kalemi gibi görülse de uzun dönemde ülke ekonomilerine önemli katkıları olabilmektedir. Örneğin bir füze sistemi ya da insansız hava uçağı askeri alanda yapılan bir harcamadır fakat bunun satışından ciddi gelirler elde edilebilmektedir. Diğer bir ifadeyle toplam refahta beklenen azalma çıktının artışı için kullanılabilecek bir itici güç olabilmektedir. İşte tam bu noktada MINT ülke grubu için askeri harcamaların mi büyümeyi yoksa büyümenin mi askeri harcamaları beraberinde getirdiği sorusuna cevap aranmaktadır. MINT ülke grubunun seçilmesinin birçok nedeni vardır. En önemli nedenlerinden biri, bu ülke grubuna yönelik literatürde herhangi bir çalışmaya rastlanmamış olması ve bu ülke grubunun birçok açıdan birbirlerine benzerlik göstermesidir. İkinci neden söz konusu ülkelerin son zamanlarda ekonomik açıdan beklenen performansı gösteremeyen BRIC ülkelerinin yerine MINT ülke grubunun aday gösterilmesi ve bu ülke grubunun stratejik bir konuma sahip olmasından kaynaklanmaktadır. Ayrıca Nijerya sürekli savaş halinde olan Afrika bölgesinde yer almaktadır. Bu sebeplerden dolayı MINT ülkeleri için SH büyük önem arz etmektedir.

Bu çalışma dört bölümden oluşmaktadır. Giriş bölümünde SH ve EB ilişkisine yönelik genel bilgiler verilmiştir. İkinci bölümde konu ile ilgili teorik çerçeve ampirik ve teorik literatür ışığında ortaya konulmuştur. Üçüncü bölümde çalışmada kullanılan veriler yöntem ve bulgular tartışılmıştır. Sonuç bölümde ise genel bir değerlendirme yapılarak politika önerilerinde bulunulmuştur.

\section{Teorik çerçeve}

Savunma harcamaları ülke güvenliğinin sağlanması anlamına geldiğinden EB'nin ön koşulu olduğu söylenebilir (Değer ve Sen, 1995: 285). Savunma harcamaları ve ekonomik büyüme arasındaki ilişki temel iki görüş etrafında şekillenmektedir. İlk olarak savunma harcamalarının milli gelir içindeki optimal düzeyi önceden belirlenmiş olsa bile cari dönemdeki tüketim ve yatırım gereksinimlerine bağlı olarak çıktı üzerinde artış ya da azalışlara neden olabilmesidir. İkinci görüş ise savunma harcamalarının, altyapı, teknolojik ilerleme ve beşerî sermaye birikimi gibi alanlarda ekonomiye sağladığı pozitif dışsallığın çıktıda bir artışa neden olabileceği şeklindedir. Aslında ilk görüş SH'lerin EB üzerindeki doğrudan, ikinci görüş dolaylı etkilerini ortaya koymaktadır. Kıt kaynakların EB'ye dolaylı ve pozitif anlamdaki katkılarının incelenmesi ise önemli bir araştırma konusudur (Giray, 2004: 188).

SH ve EB ilişkisi Benoit'in $(1973 ; 1978)$ çalışmalarından sonra dikkatleri üzerine çekmiştir. Çünkü bu çalışmalarda önceki çalışmaların aksine SH'nin EB üzerinde dolaylı olarak pozitif bir etkiye neden olabileceği belirtilmiştir. Böylece Benoit'in varsayımı üzerine yapılan çalışmalar SH'nin hem ulusal hem 
de küresel boyutta farklı açılardan birçok iktisadi değişken (örneğin istihdam beşerî sermaye gibi) üzerindeki etkilerinin ampirik olarak incelenmesine neden olmuştur. Fakat iktisatçlar SH ve EB arasındaki ilişki konusunda ortak bir noktada buluşamamışlardır (Karakaya ve Şahinoğlu, 2020: 339). Burada bahsettiğimiz önermelerin ışığında SH ile EB ilişkisini Keynesyen ve Neo-Klasik büyüme teorileri çerçevesinde ele almamız mümkün olmaktadır.

Keynesyen büyüme modelinde SH talep kanalı ile çıktı üzerinde çarpan etkisi yaratmaktadır. Diğer bir ifadeyle SH'nin toplam talepte meydana getirdiği artış sermayenin marjinal verimliliği artmakta ve EB'yi pozitif yönde etkilemektedir (Dunne, 2000: 5-6). Ayrıca bu durum daha büyük yatırımların yapılmasına da olanak sağlamaktadır. Bu açıdan, Keynesyen görüş SH'den EB'ye doğru tek yönlü bir nedensellik ilişkisi olduğunu belirtmektedir (Dakurah, Davies ve Sampath, 2001: 652; Değer, 1986: 181182).

Neo Klasik büyüme teorisi ise Keynesyen teorinin aksine SH'deki artışın para talebini artıracağını ve bu durumun ise faiz oranlarında yükselmeyi beraberinde getirerek yatırım kanalı ile EB'yi olumsuz yönde etkileyeceğini iddia etmektedir (Karakaya ve Şahinoğlu, 2020: 340). Diğer bir ifadeyle kamu harcamalarının önemli bir bileşeni olan $\mathrm{SH}^{\prime}$ nin özel yatırımlar üzerinde yarattığı dışlama etkisi (crowding out) EB'yi olumsuz yönde etkileyebilecektir (Aksoğan, Taş ve Örnek, 2013: 665). Bu durumda Neo-Klasik görüşe göre SH, EB'yi negatif yönde etkilemekte ve $\mathrm{EB}^{\prime}$ den $\mathrm{SH}^{\prime}$ ye doğru tek yönlü bir nedensellik ilişkisi olduğunu ortaya koymaktadır.

Tablo 2: Seçilmiş Ampirik Literatür

\begin{tabular}{|c|c|c|c|c|}
\hline Yazar(lar) & Dönem & Ülke(ler) & Yöntem & Sonuçlar \\
\hline Benoit (1973) & $1950-1965$ & $\begin{array}{l}\text { Gelişmiş } 44 \\
\text { Ülke }\end{array}$ & Zaman Serisi & SH ile EB arasında pozitif bir ilişki vardır. \\
\hline $\begin{array}{lll}\text { Değer ve Smith } \\
\text { (1983) }\end{array}$ & $1954-1973$ & $\begin{array}{l}\text { Gelişmiş } 44 \\
\text { Ülke }\end{array}$ & $\begin{array}{l}\text { Eşanlı } \\
\text { Denklem } \\
\text { Modeli }\end{array}$ & SH ile EB arasında negatif bir ilişki vardır. \\
\hline Joerding (1986) & $1962-1977$ & $\begin{array}{l}57 \mathrm{Az} \text { Gelişmiş } \\
\text { Ülke }\end{array}$ & Zaman serisi & SH EB' nin nedenidir. \\
\hline $\begin{array}{l}\text { Huang ve Mintz } \\
\text { (1991) }\end{array}$ & $1953-1987$ & Amerika & Zaman Serisi & SH ile EB arasında anlamlı bir ilişki yoktur. \\
\hline $\begin{array}{l}\text { Kollias re } \\
\text { Makrydakis (2000) }\end{array}$ & $1955-1993$ & Yunanistan & Zaman Serisi & SH ile EB arasında net bir ilişki yoktur. \\
\hline $\begin{array}{ll}\begin{array}{l}\text { Dakurah, } \\
(2001)\end{array} & \text { vd. } \\
\end{array}$ & $1975-1995$ & $\begin{array}{l}62 \text { gelişmekte } \\
\text { olan ülke }\end{array}$ & Zaman Serisi & $\begin{array}{l}23 \text { ülkede } \mathrm{SH}^{\prime} \text { den } \mathrm{EB}^{\prime} \text { ye doğru tek yönlü nedensellik } \\
7 \text { ülkede çift yönlü nedensellik vardır. }\end{array}$ \\
\hline Sezgin (2001) & 1956-1994 & Türkiye & Zaman Serisi & SH EB'yi pozitif yönde etkilemektedir. \\
\hline Halıcıŏglu (2004) & $1950-2002$ & Türkiye & Zaman Serisi & SH ile EB arasında negatif ilişki vardır. \\
\hline $\begin{array}{l}\text { Dunne } \\
\text { Nikolaidou }\end{array}$ & 1960-2002 & $\begin{array}{l}\text { Türkiye ve } \\
\text { Yunanistan }\end{array}$ & Zaman Serisi & SH ve EB arasında ilişki yoktur. \\
\hline Yakovlev (2007) & $1965-2000$ & 28 ülke & Zaman Serisi & SH ile EB arasında negatif ilişki vardır. \\
\hline Heo (2009) & 1954-2005 & Amerika & Zaman Serisi & SH EB arasında pozitif yönlü zayıf bir ilişki vardır. \\
\hline $\begin{array}{l}\text { Yilancı ve Özcan } \\
\text { (2010) }\end{array}$ & $1950-2006$ & Türkiye & Zaman Serisi & EB'den SH'ye doğru tek yönlü nedensellik vardır. \\
\hline Farzanegan (2014) & 1959-2007 & İran & Zaman Serisi & SH'den EB'ye tek yönlü nedensellik vardır. \\
\hline Korkmaz (2015) & $2005-2012$ & $\begin{array}{l}10 \text { Akdeniz } \\
\text { ülkesi }\end{array}$ & Panel & SH EB'yi negatif yönde etkilemektedir. \\
\hline Islam (2015) & $1988-2012$ & 41 ülke & Panel & $\begin{array}{l}\text { Düşük sanayileşme olan ülkelerde ülkelerde SH EB'yi } \\
\text { pozitif, Sanayileşmiş ülkelerde negatif etkilemektedir. }\end{array}$ \\
\hline Destek (2016) & $1998-2014$ & $\begin{array}{ll}14 & \text { NATO } \\
\text { ülkesi } & \end{array}$ & Panel & SH EB arasında çift yönlü nedensellik ilişkisi vardır. \\
\hline Topal (2018) & $1960-2016$ & Türkiye & Zaman Serisi & $\begin{array}{l}\text { SH'den } \mathrm{EB}^{\prime} \text { ye negatif ilşiki ve tek yönlü nedensellik } \\
\text { vardır. }\end{array}$ \\
\hline $\begin{array}{l}\text { Çayın ve Yapraklı } \\
\text { (2018) }\end{array}$ & 1970-2016 & Türkiye & Zaman Serisi & EB'den $\mathrm{SH}^{\prime}$ ye tek yönlü nedensellik vardır. \\
\hline Turan vd. (2018) & $1988-2016$ & 41 ülke & Panel & $\begin{array}{l}\text { Yüksek gelirli ülkelerde } \mathrm{SH}^{\prime} \text { den } \mathrm{EB}^{\prime} \text { ye tek yönlü düşük } \\
\text { gelirli ülkelerde çift yönlü nedensellik vardır. }\end{array}$ \\
\hline $\begin{array}{l}\text { Saba ve Ngepah } \\
(2020)\end{array}$ & $1990-2015$ & $\begin{array}{ll}35 & \text { Afrika } \\
\text { Ülkesi } & \end{array}$ & Panel & $\begin{array}{l}\text { SH EB arasında } 7 \text { ülkede nedensellik yok. } 2 \text { Ülkede } \\
\text { SH'den EB'ye doğru, } 12 \text { ülkede çift yönlü } 14 \text { ülke de ise } \\
\text { EB'den SH'ye doğru nedensellik ilişkisi vardır. }\end{array}$ \\
\hline $\begin{array}{l}\text { Dimitraki ve Win } \\
\text { (2020) }\end{array}$ & 1970-2015 & Ürdün & Zaman Serisi & SH EB'yi pozitif yönlü etkilemektedir. \\
\hline Azam (2020) & 1988-2019 & $\begin{array}{l}\text { OECD ülkesi } \\
\text { olmaya } 35 \text { ülke }\end{array}$ & Panel & SH EB'yi negatif yönde etkilemektedir. \\
\hline
\end{tabular}

Not: SH: Savunma harcamaları, EB: Ekonomik büyümeyi göstermektedir.

Tablo 1'de SH ve EB ilişkisi üzerine birçok zaman serisi ve panel çalışmasının olduğu ve sonuçların yöntem, dönem ve örnekleme göre farklılık gösterdiği görülmektedir. Literatürde konu ile ilgili 
çalışmalar incelendiğinde, ele alınan ülkeler, dönem, veri seti ve ekonometrik yöntem farklılıklarından dolayı ilişkinin yönü hakkında net bir fikir birliğine varılamadığı görülmektedir. Litetatürde SH ve EB ilişkisini MINT (Meksika, Endonezya, Nijerya ve Türkiye) ülke grubu için inceleyen bir çalışmaya rastlanmamıştır.

Benoit (1973) 1950-1965 dönemlerini 44 ülke için SH ile EB ilişkisini incelediği çalışma bu alandaki öncü çalışmadır. Bu çalışmada iktisat yazınına Benoit hipotezi olarak geçmiştir. Bu hipoteze yönelik sonraki çalışmalar farklılık arz etmektedir. Bu durumun ele alınan dönem, kullanılan yöntem ve değişkenlerdeki farklılıklardan kaynaklandığı düşünülmektedir. Bu bağlamda SH ve EB ilişkisini inceleyen çalışmalardan bir k1smı (Benoit, 1973; Murdoch, Chung ve Sandler, 1997; Sezgin, 2001; Rafael, 2001; Ateşoğlu, 2002; Halıcıoğlu, 2004; Yıldırım, Sezgin ve Öcal , 2005; Sümer, 2005; Wijeweera ve Webb, 2009; Feridun, Sawhney ve Shahbaz, 2011; Yurttançıkmaz, Amin ve Emsen, 2012; Yıldırım ve Öcal, 2016; Canbay ve Mercan, 2017; Ismail, 2017; Oarania ve Sandar, 2020) Keynesci yaklaşımı savunurken, (Smith, 1980; Değer, 1986; Gyimah-Brempong, 1989; Dunne ve Vougas, 1999; Batchelor, Dunne ve Saal, 2000; Galvin, 2003; Karagöl ve Palaz, 2004; Yakovlev, 2007; Alptekin ve Levine, 2012; Başar ve Künü, 2012; Khalid ve Razaq, 2015; Na ve Bo, 2013; Altay, Ekinci ve Peçe, 2013; Özsağır, 2013; Jabar,Khalid ve Razaq, 2015; Korkmaz, 2015; Manamperi, 2016; Topal, 2018; Saba ve Ngepah, 2020; Azam, 2020) Neoklasik Yaklaşımı savunmaktadır. Bazı çalışmalar ise (Biswas ve Ram, 1986; Dunne ve Nikolaidou, 2012; Papanikos, 2015; Kollias ve Paleologou 2016;) söz konusu değişkenlerin arasında önemli bir ilişkinin olmadığı ya da değişkenler arasındaki bu ilişkinin ihmal edilebilir olduğunu belirtmektedir.

\section{Veriler}

MINT ülkelerinde (Meksika, Endonezya, Nijerya, Türkiye) 1974 - 2019 yılları arasında EB ile SH arasındaki ilişkinin incelendiği bu çalışmada büyümeyi temsilen dolar cinsinden reel GSYH ve SH serisi kullanılmıştır. Değişkenlerin tümü dünya bankası veri tabanından (WDI) elde edilmiştir. GSYH serisi deflatör yardımıyla reel hale getirilip gerçek her ülkenin yıllık ortalama döviz kuru ile Amerikan dolarına dönüştürülmüştür. Çünkü SH değişkeni de Amerikan doları cinsindendir. Tüm değişkenlerin doğal logaritmaları alınmıştır. Buna göre kurulan modeller 1 ve 2 nolu eşitlikte gösterildiği gibidir.

Tablo 3: Tanımlayıcı İstatistikler

\begin{tabular}{|c|c|c|c|c|c|c|c|}
\hline & Ortalama & Maks. & Min. & Std. Hata & Skewness & Kurtosis & J.-Bera \\
\hline EB & 12.3370 & 18.1901 & 4.5515 & 3.4884 & -0.1191 & -0.0643 & $\begin{array}{l}2.5639 \\
(0.277)\end{array}$ \\
\hline SH & 9.3778 & 10.3106 & 8.2323 & 0.4563 & 2.4730 & 2.7820 & $\begin{array}{l}0.4910 \\
(0.782)\end{array}$ \\
\hline
\end{tabular}

Not: Parantez içindeki değerler p-olasılık değerleridir.

Yukarıdaki tabloda değişkenlere ait tanımlayıcı istatistikler görülmektedir. Her iki seride belirli bir ortalama ve standart hata dağılımına sahiptir J.-Bera test sonuçlarına göre seriler normal dağılıma sahiptir.

\section{Yöntem}

\section{Yatay kesit bağımlılığı ve eğim homojenliği}

Panel veri analizlerinde yatay kesit bağımlılığı (YKB) ve eğim homojenliği (EH) dikkate alınmadan yapılan tahminler yanıltıcı olabilmektedir. Bu nedenle testlere geçilmeden önce ön test olarak yapılması önerilir. Literatürde YKB ve EH'yi ölçmek için kullanılan birçok test vardır. Bu çalışmada YKB için Breusch ve Pagan (1980) (LM), Pesaran vd. (2008) (LMadj) testleri kullanılmıştır. EH'yi test etmek için ise Pesaran ve Yamagata (2008) $\tilde{\Delta}$ testi kullanılmıştır. YKB ve EH'nin test edileceği modeller aşağıda gösterildiği gibidir.

$$
\begin{array}{ll}
E B_{i t}=\alpha_{i}+\beta_{i} S H_{i t}+\mu_{i t} & \Rightarrow i=1,2, \ldots, N \text { ve } t=1,2, \ldots, T \\
S H_{i t}=b_{i}+\theta_{i} E B_{i t}+\varepsilon_{i t} & \Rightarrow i=1,2, \ldots, N \text { ve } t=1,2, \ldots, T
\end{array}
$$

1 ve 2 nolu eşitlikte $\mathrm{N}$ ve T sırasıyla ülke sayısı ve zaman boyutunu göstermektedir. Buna göre LM test istatistiği 3 nolu eşitlikte gösterilmiştir.

$L M=T \sum_{i=1}^{N-1} \sum_{j=i+1}^{N} T_{i j} \hat{\rho}_{i j}^{2} \sim \chi_{\frac{N(N-1)}{2}}^{2}$ 
$\hat{\rho}_{i j}, 1$ ve 2 nolu eşitliklerin kalıntılarının korelasyon katsayılarının tahminidir. 'Yatay kesitler arasinda bağımlılık yoktur' şeklinde kurulan temel hipotez, 'En az iki yatay kesit arasında bağımlılık vardır' birim hipotezine karşı sınanır. LM testi $\mathrm{N}<\mathrm{T}$ olduğu durumlarda kullanılmaktadır. N'nin T'ye göre büyük olduğu ve kalıntıların ikili korelasyonlarının 0 olmadığı durumlarda Pesaran vd. (2008) LM testinin değiştirilmiş bir versiyonunu kullanılmaktadır.

$L M_{\text {adj }}=\sqrt{\left(\frac{2}{N(N-1)}\right)} \sum_{i=1}^{N-1} \sum_{j=i+1}^{N} \hat{p}_{i j} \frac{(T-k) \hat{p}_{i j}^{2}-\mu_{T i j}}{\sqrt{v_{T i j}^{2}}} \sim N(0,1)$

Burada $\mathrm{k}$, bağımsız değişken sayısını, $\mu$ ve $v$ ise $\hat{p}_{i j}{ }^{\prime}$ nin sırasıyla beklenen değerini ve varyansını göstermektedir. Eğim homojenliği Pesaran ve Yamagata (2008) testi ile ölçülmüşsür. Bu testte $T \rightarrow \infty$ ve $\mathrm{N} \rightarrow \infty$ olduğu durumlarda kullanılmaktadır. Homojenliği gösteren temel hipotez $H_{0}: \beta_{i}=\beta$, heterojenliği ifade eden alternatif hipoteze $H_{1}: \beta_{i} \neq \beta_{j}$ karşı sınanır. Aslında bu test denklem $5^{\prime}$ te gösterildiği gibi Swamy testinin gelişmiş bir halidir.

$\tilde{S}=\sum_{i=1}^{N}\left(\hat{\beta}_{i}-\beta_{W F E}\right)^{\prime} \frac{x_{i}^{\prime} M_{\tau} x_{i}}{\tilde{\sigma}_{i}^{2}}\left(\hat{\beta}_{i}-\beta_{W F E}\right)$

Eşitlikteki $\hat{\beta}_{i}$ ve $\beta_{W F E}$ sırasıyla havuzlanmış EKK ve ağırlıklandırılmış sabit etkiler tahmincilerini göstermektedir. $M_{\tau}, T$ ve $\tilde{\sigma}_{i}^{2}$ ye göre düzenlenmiş tanımlayıcı matriksi ifade etmektedir. $\Delta_{\text {adj. }}$ olarak gösterilen test aşağıdaki eşitlikte gösterilmiştir.

$\Delta_{\text {adj. }}=\sqrt{N}=\left(\frac{N^{-1} \tilde{S}-k}{\sqrt{2 k(T-k-1) / T+1}}\right) \sim N(0,1)$

\section{CADF birim kök testi}

Emirmahmutoğlu ve Köse (2011) panel nedensellik analizi yapmadan önce yatay kesit bağımlılığına bakılması gerekmektedir. Çünkü testin yapılmasının ön koşullarından biri modelde yatay kesit bağımlılı̆̆ının olmasıdır. Ayrıca test Toda ve Yamamoto (1995) temelinde bir test olmasından dolayı modeldeki değişkenlerin maksimum eşbütünleşme derecelerinin bilinmesi gerekir. Bu nedenle Pesaran (2006) tarafından önerilen ve ADF testinin yatay kesit ortalamaları ile genişletilmiş CADF testi kullanılmıştır. Bu test yatay kesit bağımlılığının olduğu durumlarda kullanılan 2. kuşak bir testtir.

Otokorelasyonsuz heterojen panel model aşağıda gösterilmiştir.

$$
\Delta Y_{i t}=a_{i}+\rho_{i} Y_{i t-1}+\gamma_{i} f_{t}+\varepsilon_{i t}
$$

7 nolu eşitlikte $\Delta Y_{i t}=Y_{i t}-Y_{i t-1}{ }^{\prime}$ dir. $f_{t}$, bilinmeyen ortak faktörleri, $a_{i}$, her bir birim için sabit parametreyi. Pesaran (2006) $Y_{i t}{ }^{\prime}$ nin sirasıyla ortalaması $\bar{Y}_{i t}$ ve ortalamasının gecikmeli değerlerini $\Delta \bar{Y}_{i t}{ }^{\prime} \mathrm{yi}$ $f_{i}^{\prime}$ nin etkisini yok etmek için araç değişken olarak kullanmıştır (Yerdelen Tatoğlu, 2017: 78). Buna göre denklem aşağıdaki eşitlikte gösterildiği gibidir.

$\Delta Y_{i t}=a_{i}+\rho_{i} Y_{i t-1}+d_{0} \bar{Y}_{t-1}+d_{1} \Delta \bar{Y}_{t}+\varepsilon_{i t}$

Yukarıdaki testin $H_{0}: \rho_{i}=0$ hipotezi $H_{1}: \rho_{i}<0$ hipotezine karşı sınanır. CADF test istatistiği aşağıdaki gibidir.

$t_{i}(N, T)=\frac{\Delta Y_{i}^{\prime} \bar{M}_{w} Y_{i,-1}}{\hat{\sigma}_{i}\left(Y_{i-1}^{\prime} \bar{M}_{w} Y_{i,-1}\right)^{1 / 2}}$ 
9 nolu eşitlik ile birimler için test istatistikleri hesaplanır. Test istatistiklerinin 10 nolu eşitlikte gösterildiği gibi ortalaları alınarak IPS test istatistiğinin yatay kesitlerde genişletilmiş hali olan CIPS panel test istatistiği elde edilir (Pesaran, 2006: 267).

$C I P S=N^{-1} \sum_{i=1}^{N} C A D F_{i}$

\section{Emirmahmutoğlu ve Köse (2011) panel nedensellik analizi}

Ampirik ekonomi literatüründe nedensellik analizleri ilişkinin yönünü tespit etmek veya bir teoriyi test etmek gibi amaçlarla oldukça yaygın bir kullanım alanına sahiptir. Emirmahmutoğlu ve Köse (2011) Toda ve Yamamo (1995) temellinde geliştirilmiş bir heterojen panel nedensellik analizidir. Bu test 7 nolu eşitlikte gösterilen n değişkenli panel VAR $\left(k_{i}\right)$ modelinden hareket ederek açıklanacak olursa;

$z_{i t}=\mu_{i}+A_{i 1} Z_{i, t-1}+\cdots+A_{i k_{i}} Z_{i, t-k_{i}}+\mu_{i t} \quad i=1,2, \ldots, N \quad t=1,2, \ldots, T$

11 nolu eşitlikte $i$ ve $t$ sırasıyla birim ve zamanı göstermektedir. $\mu_{i}$ zamandan bağımsız $\mathrm{n}$ boyutundaki sabit etkileri $A_{i 1}, \ldots, A_{i k_{i}}$ birimden birime değişen $n x n$ boyutundaki sabit matris parametrelerini, $k_{i}$ her bir için değişen gecikme uzunluğunu göstermektedir. VAR sürecindeki değişkenler birim köklü ise Wald istatistikleri standart olmayan asimptotik dağılıma sahip olduğundan Granger nedensellik analizi modelde durağan olmayan değişkenler varsa durağanlaştırılamadan kullanılamaz. Bu nedenle Toda ve Yamamoto (1995) 11 nolu eşitlikteki modelde elde edilen gecikme uzunluğuna maksimum eşbütünleşme derecesinin eklendiği aşağıda gösterilen $V A R k_{i}+d \max _{i}$ modelini önermişlerdir.

$z_{i t}=\mu_{i}+A_{i 1} Z_{i, t-1}+\cdots+A_{i k_{i}} Z_{i, t-k_{i}}+\sum_{l=k_{i}+1}^{k_{i}+\operatorname{dmax}_{i}} A_{i l} Z_{i, t-1}+\mu_{i t}$

12 nolu eşitlikte $i$ ve $t$ sırasıyla $i=1,2, \ldots, N, t=1,2, \ldots, T$ şeklinde birim ve zaman boyutunu göstermektedir. Bu yaklaşımda 'nedensellik yoktur' şeklindeki sıfır hipotezi her bir birim için kurulan alternatif hipoteze karşı sınanır. Ayrıca Emirmahmutoğlu ve Köse (2011) panelin her bir birimi için elde edilen p-değerlini Fisher (1932) tarafından geliştirilen test istatistiği ile panel test istatistiği hesaplanmışlardır. Bu test istatistiği aşağıdaki gibidir.

$\lambda=-2 \sum_{i=1}^{N} \ln \left(p_{i}\right) \quad i=1,2, \ldots, N$

13 nolu eşitlikte $p_{i}$ paneldeki $i$ 'ninci kesitin Wald istatistiğine karşllık gelen p-değeridir. Bu test $2 N$ serbestlik derecesinde $\chi^{2}$ dağllımına sahiptir.

\section{Bulgular}

Aşağıdaki tablolarda yöntemleri anlatılan testlere ait sonuçlar ve açıklamaları yer almaktadır. Öncelikle YKB ve EH test sonuçları yer almaktadır. Test sonuçlarından birimler arası korelasyon diğer bir ifadeyle YKB olduğu için ikinci kuşak CADF birim kök testi tercih edilmiş ve nedensellik testine geçmeden önce değişkenlere ait maksimum eşbütünleşme dereceleri tespit edilmiştir. Son olarak ise nedensellik analizi yapılmıştır.

Tablo 4: Yatay Kesit Bağımlılı̆̆ı ve Eğim Homojenliği Test Sonuçları

\begin{tabular}{lcccc}
\hline & 1. Eşitlik & p-değeri & 2. Eşitlik & p-değeri \\
\hline LM & $59.241^{\mathrm{a}}$ & 0.000 & $21.693^{\mathrm{a}}$ & 0.001 \\
$\mathbf{L M}_{\text {adj }}$ & $75.828^{\mathrm{a}}$ & 0.000 & $11.145^{\mathrm{a}}$ & 0.000 \\
\hline \multicolumn{5}{c}{ Eğim Homojenliği } \\
\hline$\Delta_{\text {adj. }}$ & $21.586^{\mathrm{a}}$ & 0.000 & $9.988^{\mathrm{a}}$ & 0.000 \\
\hline
\end{tabular}

Not: a ve b sirasıyla \%1 ve \%5 seviyesinde anlamlılı̆̆ ifade etmektedir. 
Tablo 4'te 1 ve 2 nolu eşitliklerde belirtilen modellere ait YKB ve EH test sonuçları yer almaktadır. LM ve $\mathrm{LM}_{\text {adj }}$ testleri $\mathrm{YKB}$ 'yi $\Delta_{\text {adj. }}$ ise $\mathrm{EH}^{\prime}$ yi test etmek içindir. Test sonuçlarına göre $\mathrm{YKB}$ 'nin yatay kesit bağımlılı̆̆ yoktur ve EH'nin eğimde homojendir şeklinde kurulan temel hipotezleri reddedilmektedir. Yani modelde YKB vardır ve heterojendir.

Tablo 5: CADF Birim Kök Testi Sonuçları

\begin{tabular}{|c|c|c|c|c|c|}
\hline Ülkeler & Değişkenler & $\mathbf{L}$ & CADF t-ist. & $\mathbf{L}$ & CADF t-ist. \\
\hline & \multirow{5}{*}{ EB } & & Sabitli & & Sabitli ve Trendli \\
\hline Meksika & & 2 & -2.306 & 2 & -1.954 \\
\hline Endonezya & & 2 & -1.892 & 2 & -2.737 \\
\hline Nijerya & & 3 & -2.020 & 3 & -1.861 \\
\hline Türkiye & & 2 & -2.472 & 2 & -2.468 \\
\hline CIPS t-ist. & & & -2.172 & & -2.428 \\
\hline Meksika & \multirow{4}{*}{$\Delta \mathrm{EB}$} & 2 & $-3.453^{b}$ & 2 & $-3.733^{c}$ \\
\hline Endonezya & & 2 & $-5.623^{a}$ & 2 & $-5.540^{a}$ \\
\hline Nijerya & & 3 & -1.682 & 3 & $-3.528 c$ \\
\hline Türkiye & & 2 & $-3.137^{b}$ & 2 & $-3.508^{c}$ \\
\hline CIPS t-ist. & & & $-3.474^{a}$ & & $-3.702^{a}$ \\
\hline Meksika & \multirow{4}{*}{$\mathrm{SH}$} & 2 & -1.588 & 2 & -3.250 \\
\hline Endonezya & & 2 & -1.937 & 2 & -2.035 \\
\hline Nijerya & & 3 & -1.497 & 3 & -2.497 \\
\hline Türkiye & & 2 & -0.114 & 2 & -2.974 \\
\hline CIPS t-ist. & & & -1.284 & & -2.689 \\
\hline Meksika & \multirow{4}{*}{$\Delta S H$} & 2 & $-6.009 a$ & 2 & $-6.203^{a}$ \\
\hline Endonezya & & 2 & $-5.389^{a}$ & 2 & $-5.318^{a}$ \\
\hline Nijerya & & 2 & $-6.898^{a}$ & 2 & $-7.235^{\mathrm{a}}$ \\
\hline Türkiye & & 2 & $-5.654^{a}$ & 2 & $-5.606^{a}$ \\
\hline CIPS t-ist. & & & $-5.978^{a}$ & & $-6.090^{a}$ \\
\hline
\end{tabular}

Not: a,b,c, sırasıyla \%1, \%5 ve \%10 seviyelerinde anlamlılıkları göstermektedir. L gecikme uzunluğunu ifade etmektedir. \%1, \%5 ve \%10 seviyelerinde surasiyla kritik değerler CADF Sabitli modelde, \%-3.94, -3.29, -2.94'tür. CADF Sabitli ve Trendli modelde, $4.49,-3.78,-3.44^{\prime}$ tür. CIPS Sabitli modelde, $-2.55,-2.33,-2.21^{\prime}$ dir. CIPS Sabitli ve Trendli modelde, $-2.55,-2.33,-2.21^{\prime}$ dir. Kritik değerler Pesaran (2007) çalışmasından alınmıştır.

Tablo 5'te CADF birim kök test sonuçları görülmektedir. Test sonuçlarına göre tüm değişkenler hem sabitli hem de sabitli trendli modellerde düzey değerinde birim köklü iken birinci farklarında durağan olmaktadırlar. Diğer ifadeyle değişkenler I(1)'dir. Bu nedenle yapılacak olan nedensellik analizinde maksimum eşütünleşme derecesinin $\left(d_{\max }\right)$ bir olarak alınması gerekmektedir.

Tablo 6: Emirmahmutoğlu ve Köse (2011) Panel Nedensellik Analiz Sonuçları

\begin{tabular}{llcccc}
\hline Ülkeler & $\mathbf{k}$ & $\mathbf{E B} \rightarrow \boldsymbol{\beta} \mathbf{H}$ & p-değeri & SH $\rightarrow$ - $\mathbf{E B}$ & p-değeri \\
\hline Meksika & 3 & $7.953^{\mathrm{b}}$ & 0.047 & $18.952^{\mathrm{a}}$ & 0.0003 \\
Endonezya & 2 & 0.896 & 0.639 & 1.531 & 0.4652 \\
Nijerya & 2 & 3.899 & 0.142 & 0.284 & 0.8675 \\
Türkiye & 2 & 2.034 & 0.362 & $7.515^{\mathrm{b}}$ & 0.0234 \\
\hline Panel Sonuçları & Fisher-test & p-değeri & & & \\
& istatistiği & & & & \\
\hline EB $\not$ SH & 12.945 & 0.114 & & & \\
SH $\not$ EB & $25.694^{\mathrm{a}}$ & 0.001 & & & \\
\hline
\end{tabular}

Not: k, Schwarz Bayesian kriterine göre seçilen gecikme uzunluğunu göstermektedir. a, b, c, sırasıyla \%1, \%5 ve \%10 seviyesinde anlamlılıkları ifade etmektedir.

Tablo 6' da panel nedensellik analiz sonuçları görülmektedir. Test sonuçlarına göre Meksika için EB ile

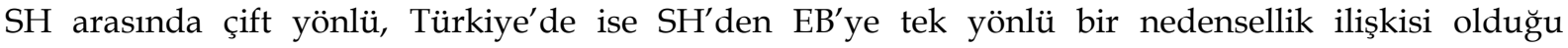
görülmektedir. Ayrıca panelin geneli için sadece $\mathrm{SH}^{\prime}$ den $\mathrm{EB}^{\prime}$ ye doğru tek yönlü nedensellik tespit edilmiştir. Meksika ekonomisinde büyüme ve savunma harcamaları karşılıklı olarak birbirlerini etkilemektedir. Türkiye'de ise savunma harcamaları çıktıda bir artışa neden olmaktadır. Diğer bir ifadeyle MINT ülkelerin genelinde olduğu gibi Türkiye'de de savunma harcamaları çekişli büyüme hipotezi geçerlidir.

\section{Sonuç}

Devletin asli görevi iç ve dış tehditlere karşı vatandaşlarını korumaktır. Bu durum savunma harcamalarını zorunlu hale getirmektedir. Bu harcamalar kamu harcaması niteliğinde olup çıktı üzerinde etkili olabilmektedir. Fakat ilişkinin yönü konusunda farklılıklar vardır. Aslında literatürdeki çalışmalar genel olarak bu değişkenliğin ülkelerin ekonomik şartları, olanakları ve teknolojik gelişmişlik farklarından kaynaklandığını ortaya koysada tam anlamıyla teorik bir çıkarım yapmak oldukça güçtür. $\mathrm{Bu}$ açıdan, ülkelerin savunma harcamaları ile ekonomik büyüme arasındaki dengeyi iyi kurmaları gerekmektedir. Böyle yaptıkları takdirde askeri ve ekonomik yönden güçlü bir ülke olabileceklerdir. 
Bu çalışmada 1974-2019 dönemi ekonomik büyüme ve savunma harcamaları ilişkisi panel nedensellik analizi ile incelenmiştir. Dört ülkeden oluşan (Meksika, Endonezya, Nijerya ve Türkiye) MINT ülkelerinde ve Türkiye için savunma harcamaları çekişli büyüme hipotezi, dolayısıyla Keynesyen görüşü desteklemektedir. Nijerya ve Endonezya için yansızlık hipotezi geçerlidir. Ayrıca Meksika hem büyüme hem de savunma harcamaları karşılıklı olarak birbirlerini etkilediklerinden dolayı hem büyüme çekişli hem de savunma harcamaları çekişli büyüme hipotezlerinin geçerli olmuştur. Panelin geneli için elde edilen sonuca göre, Keynesyen görüş desteklenmektedir. Bu açıdan elde edilen sonuçlar literatürde yer alan Benoit, 1973; Murdoch vd., 1997; Sezgin, 2001; Rafael, 2001; Ateşoğlu, 2002; Halıcıoğlu, 2004; Yıldırım, vd, 2005; Sümer, 2005; Wijeweera ve Webb, 2009; Feridun, vd., 2011; Yurttançıkmaz, vd. 2012; Yıldırım ve Öcal, 2016; Canbay ve Mercan, 2017; Ismail, 2017; Oarania ve Sandar, 2020 çalışmalar ile benzerlik göstermektedir.

Ekonomik açıdan değerlendirildiğinde, elde edilen neticeler gelişmekte olan bir ülke olarak Türkiye'de askeri harcamaların ekonomik büyüme üzerindeki olumlu etkisini vurgulayıcı niteliktedir. Türkiye'nin de aralarında yer aldığı bu ülke grubunda savunma sanayisinde diş ticaret açı̆̆ı veren ülkelerin de yerli üretimi artırmaya yönelik politikalar geliştirmesi önerilmektedir. Analiz sonuçlarının 1şı̆̆ında değerlendirecek olursak, savunma sanayine yönelik yapılan yatırımların ülkelere hem ulusal güvenliği hem de ticaret dengesini sağlamaları açısından olumlu katkı sağlamaktadır. MINT ülke topluluğunun bulunduğu coğrafyadalardaki stratejik konum, gerilim ve istikrarsızlıklar göz önünde bulundurulduğunda SH'nin gelecekte de artışını sürdürüceği düşünülmektedir. Politika yapıcıların gelecekte önemli potansiyele sahip olan bu ülkelerde SH yapılırken sağlık, alt yapı, çevre ve eğitim gibi diğer harcama kalemleri üzerinde meydana getireceği etkiyi gözardı etmemeleri gerekmektedir. Bu nedenle konu ile ilgili gelecekte çalışma yapacak araştırmacıların SH'larını etkileyen adı geçen değişkenlerle incelemesi önerilmektedir.

\section{Hakem Değerlendirmesi / Peer-review:}

Diş bağımsız

Externally peer-reviewed

\section{Çıkar Çatışması / Conflict of interests:}

Yazar(lar) çıkar çatışması bildirmemiştir.

The author(s) has (have) no conflict of interest to declare.

\section{Finansal Destek / Grant Support:}

Yazar bu çalışma için finansal destek almadığını beyan etmiştir.

The author declared that this study has received no financial support.

\section{Yazar Katkıları / Author Contributions:}

Fikir/Kavram/Tasarım - Idea/Concept/Design: SD.,I.H.P. Veri Toplama ve/veya İşleme - Data Collection and/or Processing: S.D. Analiz ve/veya Yorum - Analysis and/or Interpretation: S.D. Kaynak Taramas1 Literature Review: S.D.,I.H.P. Makalenin Yazımı - Writing the Article: S.D., I.H.P. Eleştirel İnceleme Critical Review: SD.,I.H.P, Onay - Approval: S.D., İ.H.P.

\section{Kaynakça / References}

Aksoğan, G., Taş, S., \& Örnek, İ. (2013). Türkiye' de Savunma Harcamaları, Büyüme ve Gelir Eşitsizliği, 1970-2008: Ekonometrik Bir İnceleme. Gaziantep Üniversitesi Sosyal Bilimler Dergisi, 12(3), 659-382.

Alptekin, A., \& Levine, P. (2012). Military expenditure and economic growth: A meta-analysis. European Journal of Political Economy, 28(4), 636-650.

Altay, H., Ekinci, A., \& Peçe, M. A. (2013). Ortadoğu'da Terörün Ekonomik Etkileri: Türkiye, Misır ve Suudi Arabistan Üzerine Bir İnceleme. Dumlupınar Üniversitesi Sosyal Bilimler Dergisi, (37).

Ateşoğlu, H. S. (2002). Defense Spending Promotes Aggregate Output in The United States-Evidence From Cointegration Analysis. Defence and Peace Economics, 13(1), 55-60. 
Azam, M. (2020). Does military spending stifle economic growth? The empirical evidence from nonOECD countries. Heliyon, 6(12), e05853.

Başar, S., \& Künü, S. (2012). Savunma Harcamalarının İktisadi Büyümeye Etkisi. Sosyal Bilimler Enstitüsü Dergisi. 10(1), 1-30.

Batchelor, P., Dunne, J. P., \& Saal, D. S. (2000). Military spending and economic growth in South Africa. Defence and peace economics, 11(4), 553-571.

Benoit, E. 1973. Defense and Growth in Developing Countries. Boston, MA: Heath, Lexington Books.

Benoit, E. (1978). Growth and Defense in Developing Countries. Economic Development and Cultural Change, 26(2), 271- 280.

Biswas, B., \& Ram, R. (1986). Military Expenditures and Economic Growth in Less Developed Countries: An Augmented Model and Further Evidence. Economic Development and Cultural Change, 34(2), 361372.

Breusch, T. S., \& Pagan, A. R. (1980). The Lagrange Multiplier Test and Its Applications to Model Specification in Econometrics. The Review of Economic Studies, 47(1), 239-253.

Gyimah-Brempong, K. (1989). Defense spending and economic growth in Subsaharan Africa: an econometric investigation. Journal of Peace Research, 26(1), 79-90.

Canbay Ş., \& Mercan D. (2017). Savunma Harcamalarının Ekonomik Büyüme ve Cari İşlemler Dengesine Etkisi: Türkiye Örneği. Journal of Emerging Economies and Policy, 2(2), 86-104.

Çayın, M., \& Yapraklı, S. (2018). Defence Expenditures, Economic Growth and Current Account Deficit: Analysis of Causality on Turkey. Emprical Studies on Growth, Edit: Gökhan Karhan, Mücahit Çayın, Yunus Aşçı, Gazi Kitabevi, 51-63.

Dakurah, H., Davies, S. P., \& Sampath, R. K. (2001). Defense Spending and Economic Growth in Developing Countries: A Causality Analysis. Journal of Policy Modeling, 23, 651-658.

Değer, S. (1986). Economic Development and Defense Expenditure. Economic Development and Cultural Change. 35(1). 179-196.

Değer, S., \& Sen, S. (1995). Military expenditure and developing countries. Handbook of defense economics, 1, 275-307.

Değer, S., \& Smith, R. (1983). Military expenditure and growth in less developed countries. Journal of conflict resolution, 27(2), 335-353.

Destek, M. A. (2016). Is the causal nexus of military expenditures and economic growth asymmetric in G-6. Journal of Applied Research in Finance and Economics, 1(1), 1-8.

Dimitraki, O., \& Win, S. (2020). Military Expenditure Economic Growth Nexus in Jordan: An Application of ARDL Bound Test Analysis in The Presence of Breaks. Defence and Peace Economics, 118.

Dunne, J. P. (2000). The economic effects of military expenditure in developing countries. Economics Group, Middlesex University Business School.

Dunne, J. P., \& Nikolaidou, E. (2012). Defence Spending and Economic Growth in the EU15. Defence and Peace Economics, 23(6), 537-548.

Dunne, P., \& Vougas, D. (1999). Military spending and economic growth in South Africa: A causal analysis. Journal of Conflict Resolution, 43(4), 521-537.

Emirmahmutoğlu, F., \& Köse, N. (2011). Testing for Granger Causality in Heterogeneous Mixed Panels. Economic Modelling, 28(3), 870-876.

Erbaykal, E. (2007). Türkiye'de Savunma Harcamaları ve Ekonomik Büyüme İlişkisi. Balıkesir Üniversitesi Sosyal Bilimler Enstitüsü, Yüksek Lisans Tezi, Balıkesir.

Farzanegan, M. R. (2014). Military spending and economic growth: the case of Iran. Defence and Peace Economics, 25(3), 247-269.

Feridun, M., Sawhney, B., \& Shahbaz, M. (2011). The impact of military spending on economic growth: the case of North Cyprus. Defence and Peace Economics, 22(5), 555-562.

Fisher, R.A. (1932). Statistical Methods for Research Workers, 4th edition. Oliver and Boyd, Edinburgh. 
Galvin, H. (2003). The impact of defence spending on the economic growth of developing countries: a cross-section study. Defence and peace economics, 14(1), 51-59.

Giray, F. (2004). Savunma harcamaları ve ekonomik büyüme. Cumhuriyet Üniversitesi İktisadi ve İdari Bilimler Dergisi, 5(1), 188-189.

Halıcıoğlu, F. (2004). Defense Spending and Economic Growth in Turkey: An Empirical Application of New Macroeconomic Theory, Review of Middle East Economics and Finance 2(3), 193-201.

Heo, U. (2009). The Relationship between Defense Spending and Economic Growth in the United States, Political Research Quarterly, 63(4), 760- 770.

Huang, C., \& Mintz, A. (1991). Defence Expenditures and Economic Growth: The Externality Effect. Defence and Peace Economics, 3(1), 35-40.

Islam, M. N. (2015). Economic growth, repression, and state expenditure in non-democratic regimes. European Journal of Political Economy, 37, 68-85.

Ismail, S. (2017). Military Expenditure and Economic Growth in South Asian Countries: Empirical Evidences. International Journal of Economics and Financial Issues, 7(3), 318-325.

Jabar, M. A., Khalid, M. A., \& Razaq, A. (2015). The Impact of Military Spending on Economic Growth: Evidence from the US Economy. Research Journal of Finance and Accounting, 6(7), 183-190.

Joerding, W. (1986). Economic Growth and Defense Spending: Granger Causality. Journal of Development Economics, 21(1), 35-40.

Karagöl, E., \& Palaz, S. (2004). Does Defence Expenditure Deter Economic Growth in Turkey? A Cointegration Analysis, Defence and Peace Economics 15(3), 289-298.

Karakaya, C., \& Sahinoglu, T. (2020). Savunma Harcamaları ve Ekonomik Büyüme İlişkisi: Türkiye Örneği. Business and Economics Research Journal, 11(2), 335-351.

Khalid, M. A., \& Razaq, M. A. J. A. (2015). The Impact of Military Spending on Economic Growth: Evidence from the US Economy. Catalyst, 6(7), 183-190.

Kollias, C., \& Makrydakis, S. (2000). A note on the causal relationship between defence spending and growth in Greece: 1955-93. Defence and peace economics, 11(1), 173-184.

Kollias, C., \& Paleologou, S. M. (2016). Investment, Growth and Defense Expenditure in The EU15: Revisiting The Nexus Using SIPRI's New Consistent Dataset. The Economics of Peace and Security Journal, 11(2), 21-34.

Korkmaz, S. (2015). The Effect of Military Spending on Economic Growth and Unemployment in Mediterranean Countries. International Journal of Economics and Financial Issues 5(1), 273-280.

Manamperi, N. (2016). Does military expenditure hinder economic growth? Evidence from Greece and Turkey. Journal of Policy Modeling, 38(6), 1171-1193.

Murdoch, J. C., PI, Chung-R., \& Sandler, T. (1997). The Impact of Defense and Non-Defense Public Spending on Growth in Asia and Latin America. Defense and Peace Economics, (8),205- 224.

Na, H., \& Bo, C. (2013). Cooperation for A Peaceful and Sustainable World Part 2: Military Expenditure and Economic Growth in South Asia. Contributions to Conflict Management, Peace Economics And Development, 20, 213-223.

Özsağır, A. (2013). Askeri darbe ve müdahalelerin ekonomik performans üzerine etkisi: Türkiye örneği. Gaziantep University Journal of Social Sciences, 12(4).

Pan, C. I., Chang, T., \& Wolde-Rufael, Y. (2015). Military Spending and Economic Growth in The Middle East Countries: Bootstrap Panel Causality Test. Defence and Peace Economics, 26(4), 443-456.

Papanikos, G. T. (2015). Military Spending, International Trade and Economic Growth in the Mediterranean Basin. Athens Journal of Mediterranean Studies, 1(2), 187-194.

Pesaran, M. H. (2006). Estimation and inference in large heterogeneous panels with a multifactor error structure. Econometrica, 74(4), 967-1012.

Pesaran, M. H. (2007). A Simple Panel Unit Root Test in The Presence of Cross-Section Dependence. Journal of applied econometrics, 22(2), 265-312. 
Pesaran, M. H., \& Yamagata, T. (2008). Testing Slope Homogeneity in Large Panels. Journal of econometrics, 142(1), 50-93.

Pesaran, M. H., Ullah, A., \& Yamagata, T. (2008). A Bias-Adjusted LM Test of Error Cross-Section Independence. The Econometrics Journal, 11(1), 105-127.

Saba, C. S., \& Ngepah, N. (2020). Convergence in Military Expenditure and Economic Growth in Africa and Its Regional Economic Communities: Evidence from a Club Clustering Algorithm. Cogent Economics \& Finance, 8(1), 1832344, 3586-3606.

Saunders, P. (1993). Recent Trends in the Size and Growth of Government in OECD Countries. The Growth of the Public Sector, (Ed: Norman Gemmell), England, Edward Elgar Publishing Limited, 17-33.

Sezgin, S. (2001). An Empirical Analysis of Turkey's Defence-Growth Relationships with A MultiEquation Model (1956-1994). Defence And Peace Economics, 12(1), 69-86.

Smith, R.P. (1980). The Demand for Military Expenditure. Economic Journal, 90 (360), 811-820.

Sümer, K. K. (2005). Savunma Harcamalarının Ekonomik Büyüme Üzerine Etkisinin İncelenmesi. Güvenlik Stratejileri Dergisi, 1(01), 82-91.

SIPRI The Sıpr Military Expenditure Database (2017). https://www.sipri.org/databases (Erişim Tarihi: 24.04 2021).

Toda, H. Y., \& Yamamoto, T. (1995). Statistical Inference in Vector Autoregressions with Possibly Integrated Processes. Journal of econometrics, 66(1-2), 225-250.

Topal, M. H. (2018). Türkiye'de Askeri Harcamaları ile Ekonomik Büyüme Arasındaki İlişkinin Bir Analizi (1960-2016). Maliye Dergisi, 174, 175-202.

Turan, T., Karakaş, M., \& Özer, H. A. (2018). Askeri Harcamalar ve Ekonomik Büyüme İlişkisi: Panel Eşbütünleşme ve Nedensellik Analizi. Maliye Dergisi, 175, 140-153.

Wijeweera, A., \& Webb, M. J. (2009). Military Spending and Economic Growth in Sri Lanka: A Time Series Analysis. Defence and Peace Economics, 20(6), 499-508.

Yakovlev, P. (2007). Arms Trade, Military Spending and Economic Growth. Defence and Peace Economics, $18(4), 317-338$.

Yerdelen Tatoğlu, F. (2017). Panel Zaman Serileri Analizi Stata Uygulamalı. Beta Basım Yayın Dağıtım A.Ş., Birinci Baskı, ISBN: 978-605-242-028-7, 356.

Yılancı, V. \& Özcan, B. (2010). Yapısal Kırılmalar Altında Türkiye için Savunma Harcamaları ile GSMH Arasındaki İlişkinin Analizi. CU. İ̈BF. Dergisi, 11(1), 21-33.

Yildirim, J., \& Öcal, N. (2016). Military expenditures, economic growth and spatial spillovers. Defence and Peace Economics, 27(1), 87-104.

Yıldırım, J. Sezgin, S. \& Öcal, N. (2005). Military Expenditure and Economic Growth in Middle Eastern Countries: A Dynamic Panel Data Analysis, Defense and Peace Economics, 283-295.

Yurttançıkmaz, Z. Ç., Amin, A., \& Emsen, Ö. (2012). Askeri Harcamalar, Ambargo ve Ekonomik Büyüme: İran Üzerine Bir Uygulama. Atatürk Üniversitesi İktisadi Ve İdari Bilimler Dergisi, 26(2), 171190. 